\title{
On-line detection and quantification of trace impurities in vaporisable samples by direct liquid introduction process mass spectrometry
}

\author{
Andrew W. Owen, ${ }^{\mathrm{a}}$ Alison Nordon, ${ }^{a}{ }^{*}$ David Littlejohn, ${ }^{\mathrm{a}}{ }$ Thomas P. Lynch, ${ }^{\mathrm{b},}{ }^{1}$ J. Steven \\ Lancaster $^{\mathrm{b}, 2}$ and Robert G. Wright ${ }^{\mathrm{c}}$
}

a WestCHEM, Department of Pure and Applied Chemistry and CPACT, University of Strathclyde, 295 Cathedral Street, Glasgow, G1 1XL, UK.

${ }^{\mathrm{b}}$ Hull Research and Technology Centre, BP Chemicals, Hull, HU12 8DS, UK.

${ }^{c}$ Thermo Fisher Scientific, Winsford, Cheshire, CW7 3GA, UK.

${ }^{1}$ Present address: Technology Centre, BP, Pangbourne, Reading, RG8 7QR, UK.

${ }^{2}$ Present address: Domino Printing Sciences, Cambridge, CB23 8TU, UK.

*denotes authors to whom correspondence should be sent

David Littlejohn

Email: d.littlejohn@strath.ac.uk; tel: +44(0)141 548 2067; fax: +44(0)141 5484212

Alison Nordon

Email: alison.nordon@strath.ac.uk; tel: +44(0)141 548 3044; fax: +44(0)141 5484212

\begin{abstract}
A thermal vaporiser has been designed for analysis of liquid streams by a process mass spectrometer normally used for gas analysis. Concentrations of benzene, toluene and oxylene at $\mathrm{mg} \mathrm{kg}^{-1}$ levels in ethanol were determined from continuous vaporisation of the liquid. Ions with $\mathrm{m} / \mathrm{z}$ values of $39,57,73,77,78,91,92$ and 106 were selected and the optimal regression model (multiple linear regression with mean-centring) was found using an automated design of experiments approach to calibration model selection. It was discovered that the linearity of the response allowed excellent calibration to be performed using only four standards (at 0 and $110 \mathrm{mg} \mathrm{kg}^{-1}$ for each of the three analytes) and that there were minimal inter-analyte interferences. The detection limit of benzene, toluene and o-xylene was $0.5,0.8$ and $0.5 \mathrm{mg} \mathrm{kg}^{-1}$, respectively. Differences between the actual and predicted concentrations, expressed as a percentage of the actual concentrations, for $27-82 \mathrm{mg} \mathrm{kg}^{-1}$ of benzene, toluene and o-xylene were $0.5-1.4 \%, 0.0-0.4 \%$ and $0.3-1.6 \%$, respectively, while the relative standard deviations were $1.3-2.6 \%, 1.0-2.5 \%$ and $1.1-2.3 \%$,
\end{abstract}


respectively. Detection of $3 \mathrm{mg} \mathrm{kg}^{-1}$ changes in the concentration of each of the analytes (at the $36 \mathrm{mg} \mathrm{kg}^{-1}$ level) was also demonstrated, indicating the sensitivity of the technique and the potential ability of the procedure to detect minor deviations in the specification of process streams from continuous analysis. 


\section{Introduction}

Mass spectrometry is well established as a process analysis technique, with examples reported for the analysis of gaseous or volatile samples across a range of industries such as fermentation, ${ }^{1}$ iron and steel, ${ }^{2-4}$ semiconductor, ${ }^{5,6}{ }^{6}$ petrochemical $^{2,4,7}$ and chemical. ${ }^{2,8}$ Quadrupole or magnetic sectors instruments are typically used with electron ionisation. The analysis of liquid samples by process mass spectrometry is not nearly as common as for gases. While there have been a number of studies reporting the use of atmospheric pressure ionisation (API) techniques for on-line analysis of liquid samples in the laboratory, ${ }^{9-11}$ they currently lack the robustness required for use in a process environment and quantitative results have yet to be demonstrated in many cases. Liquid process samples are typically analysed by gas chromatography (GC) or membrane inlet mass spectrometry (MIMS). GC has the advantages that it is an established technique, and has good sensitivity and resolving power. The disadvantages are the time taken to perform an analysis and that different columns are required for different types of analyte and, therefore, column switching or more than one instrument may be required in process monitoring. MIMS offers fast detection times and can be used to significantly enhance detection of analytes. However, there is little advantage in using a membrane interface for the determination of trace impurities that are chemically similar to the bulk sample, especially in the case of small polar molecules.

Vaporisation of discrete liquid samples into a process mass spectrometer has been achieved via a heated auto-injector, ${ }^{12-14}$ a modified GC oven, ${ }^{15}$ and a programmable thermal vaporiser (PTV) injector and syringe pump. ${ }^{16}$ These systems are not ideal for continuous sampling operation as they suffer from gas concentration fluctuations due to the imprecision of vaporisation as well as the effects of dilution in the carrier gas. This paper reports on the development and use of a simple vaporising device that allows stable, continuous on-line analysis of liquid samples by process mass spectrometry. To simulate a continuous process stream with varying trace analyte concentrations, a quaternary high performance liquid chromatography (HPLC) pump was used to create tertiary mixtures of $\mathrm{mg} \mathrm{kg}^{-1}$ concentrations of benzene, toluene and o-xylene (BTX) in ethanol which were introduced to the vaporising device for direct analysis by mass spectrometry with electron ionisation. 


\section{Experimental}

\section{Magnetic sector mass spectrometer}

The mass spectrometer used was a Thermo Electron Prima 600S (Thermo Fisher Scientific, Cheshire, UK), which is normally applied to process gas analysis. It is a magnetic sector instrument that has an electron multiplier detector for low intensity ions and a Faraday cup for high intensity ions. The vapours from the liquid sample streams were transported from the vaporiser through a capillary inlet tube, heated to approximately $180{ }^{\circ} \mathrm{C}$, to the ion source via a molecular leak and bypass. The ion dwell time was set to $1 \mathrm{~s}^{-1}{ }^{-1}$ and the Penning pressure was 9 nbar. The instrument was operated under standard conditions without any special tuning to improve performance for on-line analysis of liquids.

\section{Vaporising interface}

Glass lined tubing (SGE Analytical Science, UK), with an internal diameter of $1.0 \mathrm{~mm}$, was wrapped around a metal block that was heated by a $350 \mathrm{~W}$ cartridge heater. A thermocouple was inserted in to the heater block and connected to a temperature control unit which controlled the power supply to the cartridge heater (Figure 1). The vaporiser was housed in a thermally insulated box and additionally, the heater block was wrapped in glass wool to aid uniform heating. The temperature controller was tuned at the set temperature of $180.0^{\circ} \mathrm{C}$ and, once stable, was held at that temperature to within $\pm 0.2^{\circ} \mathrm{C}$. The heated transfer capillary of the mass spectrometer was connected to one end of the tubing via a tee which allowed excess vapour to vent. The advantage of this approach is that stable analysis is achieved because any fluctuations in fluid flow will not affect the composition of the gas, as is the case with approaches using a carrier gas that require precise metering of flow to achieve stable gas delivery. Furthermore, as the gas entering the mass spectrometer is only the vaporised sample, the maximum possible sensitivity is achieved. Stable operation was demonstrated for over 8 hours; as this was a prototype device, only supervised operation within laboratory working hours was permissible.

\section{Quaternary HPLC pump}

A Unicam Crystal 200 quaternary HPLC pump was used to provide a flow of ethanol containing different levels of benzene, toluene and o-xylene, to simulate a process stream. The vaporiser is quite insensitive to flow rates and so a flow of $1.0 \mathrm{~mL} \mathrm{~min}^{-1}$ was used to 
reduce the sample change-over times. The four solvent bottles, solvent tubing, frits and pump were washed with the same ethanol to be used during the analysis. The bottles were filled with ethanol and sparged with $\mathrm{N}_{2}$; three of the solvent bottles were spiked with benzene, toluene or o-xylene to give a concentration of about $110 \mathrm{mg} \mathrm{kg}^{-1}$. The bottles were sealed to the atmosphere with the balance gas being made up of pure nitrogen. The outlet tubing from the pump was $1 / 16$ " O.D. 316 stainless steel and was connected directly to the tubing of the vaporiser. A schematic of the connection of the pump, vaporiser and mass spectrometer is shown in Figure 2.

\section{Reagents}

AnalaR grade benzene, toluene and o-xylene, and GPR grade ethanol (Sigma-Aldrich, UK) were used. Oxygen-free nitrogen (BOC, UK) was used for sparging the solvents and maintaining the head space pressure.

\section{Sample preparation}

The quaternary pump controller was used to produce different concentrations of benzene, toluene or o-xylene (BTX) in ethanol, individually and as mixtures, as indicated in Table 1. When the composition of the sample flow to the vaporiser and mass spectrometer was altered, the intensity at the selected ion masses was monitored and when the signals stabilised, normally 10 scans were made over about 2 min.

\section{Data analysis}

Data were acquired from the mass spectrometer using GasWorks (Build 217, Thermo Fisher Scientific, Cheshire) with ion intensities saved as comma separated variable files. All data analysis was performed in the Matlab environment (Version 6.5; Mathworks, Natick, USA) using PLS_Toolbox 3.0 (Eigenvector Research Inc., Washington, USA).

\section{Ion selection}

Magnetic sector mass spectrometers with flat-topped peaks are more stable to ion overlap by analytes compared to quadrupole instruments. ${ }^{4}$ Ions were selected on the basis of their multivariate leverage. The multivariate leverage was calculated for the ions in the pure component spectra of the analytes of interest, which were obtained from the NIST spectral library; ${ }^{17}$ those ions with the highest leverage were selected. In a previous study of mixtures 
of benzene, toluene, o-xylene and methyl tert-butyl ether in ethanol, ${ }^{18}$ ions with $\mathrm{m} / \mathrm{z}$ values of 39, 57, 73, 77, 78, 91, 92 and 106 were selected using this approach. Although the ion with a $\mathrm{m} / \mathrm{z}$ of 57 arises from methyl tert-butyl ether, its inclusion had no adverse effect on the results obtained when methyl tert-butyl ether was not present in a sample. Therefore, the same eight ions were monitored in the present study. The ion with a $\mathrm{m} / \mathrm{z}$ value of 48 , which can be attributed to $\left[\mathrm{C}_{2} \mathrm{H}_{5}{ }^{18} \mathrm{OH}\right]^{+}$, was also monitored to allow measurement of a solvent ion with the electron multiplier detector. Mass spectra of benzene, toluene and o-xylene from the NIST spectral library ${ }^{17}$ are given in Figure 3. The vertical dashed lines indicate which ions were monitored. The main fragments that contribute to the selected ions are given in Table 1. An example of how the ion intensities changed when the analysed stream was altered from pure ethanol to ethanol containing $111 \mathrm{mg} \mathrm{kg}^{-1} \mathrm{o}$-xylene is shown in Figure 4. Initially, the intensities recorded for the ions shown can be considered as a background level in the presence of ethanol. However, when o-xylene was added, the ions that can be attributed to oxylene, i.e. those with a $\mathrm{m} / \mathrm{z}$ of 78, 91, 92 and 106, all showed an increase in intensity.

\section{Modelling of data}

Ten repeat mass spectra for samples 1 to 4 and samples 5 to 17 (Table 2) were used for calibration and validation, respectively. The data were normalised to ethanol $(\mathrm{m} / \mathrm{z} 48)$ to correct for any flow fluctuations (a minor issue for reasons mentioned previously) or ageing of the multiplier. The optimum pre-processing method and regression model were selected using an automated design of experiments approach. ${ }^{19}$ With this approach, calibration model parameters are considered as factors and the values that individual factors can take as levels. In this study, the factors (and levels) considered within a mixed level factorial design were regression method (partial least squares 2 (PLS2), principal component regression (PCR) and multiple linear regression (MLR)), centring (none and mean centring), and number of components ( 1 - 6; for PLS2 and PCR only). The root mean square error of calibration and prediction, RMSEC and RMSEP, respectively, were calculated for each of the different models. The RMSEC and RMSEP values, i.e. responses, for each model were then used to assess the main effects of the factors and interactions between pairs of factors, and thus determine the optimum calibration model parameters. The best results were obtained using a MLR model with mean centring. 


\section{Results and discussion}

\section{Validation of model}

When just two levels $\left(0\right.$ and $\left.110 \mathrm{mg} \mathrm{kg}^{-1}\right)$ were used for calibration (samples 1 to 4 in Table 2) the predicted concentrations for samples 5 to 17 in Table 2 agreed well with the actual concentrations, as shown in Tables $3-5$. Prediction of benzene is slightly less accurate for samples 14 to 17 (average bias of $-0.84 \mathrm{mg} \mathrm{kg}^{-1}$ ), which contain all three analytes, than for samples 5, 8 and 11 (average bias of $0.13 \mathrm{mg} \mathrm{kg}^{-1}$ ), which contain only benzene. There is also a small decrease in the precision of the results for benzene when all three analytes are present (average relative standard deviation (RSD) of $1.7 \%$ for samples 5, 8 and 11 compared to $2.2 \%$ for samples 14 to 17 ). In the absence of benzene and o-xylene, the concentration of toluene is under-predicted by, on average, $0.63 \mathrm{mg} \mathrm{kg}^{-1}$ (see samples 6,9 and 12). When benzene and o-xylene are also present, as in samples 14 to 17 , the predicted concentrations of toluene generally exhibit a small positive bias of, on average, $0.55 \mathrm{mg} \mathrm{kg}^{-1}$ and are slightly less precise compared to those for samples 6, 9 and 12 (average RSD of 2.1\% compared to $1.2 \%$ ). While the accuracy of prediction for $\mathrm{o}-\mathrm{xylene}$ is relatively unaffected by the presence of benzene and toluene, the results show a slight decrease in precision (RSD of $1.9 \%$ for samples 14 to 17 compared to $1.3 \%$ for samples 7, 10 and 13). However, given that any changes in accuracy and precision are small, it can be concluded that there are minimal interanalyte interferences for the concentrations of the analytes considered. The average percent errors (given by the magnitude of the difference between the actual and predicted concentrations, expressed as a percentage of the actual concentration) for prediction of $27-$ $82 \mathrm{mg} \mathrm{kg}^{-1}$ of benzene, toluene and o-xylene were $0.5-1.4 \%, 0.0-0.4 \%$ and $0.3-1.6 \%$, respectively. For the three analytes, it can be seen from Tables $3-5$ that the standard deviation reduces with concentration suggesting the noise is heteroscedastic. The detection limit was calculated from 3 times the standard deviation of the average prediction $(n=6)$ for each analyte when its actual concentration was $0 \mathrm{mg} \mathrm{kg}^{-1}$. The values obtained for benzene, toluene and o-xylene were $0.5,0.8$ and $0.5 \mathrm{mg} \mathrm{kg}^{-1}$, respectively.

\section{Trace deviation detection}

In some process control applications, on-line detection of minor deviations in the specification of a process stream is required. An experiment was performed to see if $3 \mathrm{mg} \mathrm{kg}^{-1}$ deviations in the concentrations of benzene, toluene or o-xylene at about $36 \mathrm{mg} \mathrm{kg}^{-1}$ (sample 14 in Table 1) could be detected. These results were obtained 1 (scans 1 
to 115 ) and 2 (scan 116 onwards) days after the calibration samples had been analysed. The flow of sample 14 was vaporised into the mass spectrometer and once the ion signals had stabilised, the concentration of each of the analytes in the ethanol stream was reduced in turn by $3 \mathrm{mg} \mathrm{kg}^{-1}$ and the calibration model used to predict the analyte concentrations on a scan by scan basis (see Figure 5). It can be seen that it took approximately 50 scans (10 mins) for the composition of the stream to stabilise after a change was introduced.

Figure 5 shows that the predictions are still accurate for at least 2 days after the calibration model was prepared. There is a delay of over 8 hours between scans 115 and 116 highlighting the stability of the mass spectrometer and vaporiser. For example, the predicted concentration (mean \pm one standard deviation) for o-xylene on day 1 (scans 1 to 115) was $36.5 \pm 0.7 \mathrm{mg} \mathrm{kg}^{-1}$ whereas on day 2 (scans 116 to 231) the concentration was $36.3 \pm 0.8$ $\mathrm{mg} \mathrm{kg}^{-1}$. During the periods when the benzene (scans 232 to 512 ) and toluene (scans 513 to 800) concentrations were decreased, the predicted concentration of o-xylene was $35.9 \pm 0.8$ and $36.2 \pm 0.8 \mathrm{mg} \mathrm{kg}^{-1}$, respectively, highlighting the selectivity of the MLR model. After reducing the o-xylene content by $3 \mathrm{mg} \mathrm{kg}^{-1}$ and allowing the stream composition to stabilise, the predicted concentration was $33.9 \pm 0.7 \mathrm{mg} \mathrm{kg}^{-1}$ (scans 851 to 1000). This compares to actual concentrations of 36.6 and $33.6 \mathrm{mg} \mathrm{kg}^{-1}$ during scans 1 to 801 and 851 to 1000 , respectively. All the analytes show detectable changes, greater than 3 times the standard deviation (at the $36 \mathrm{mg} \mathrm{kg}^{-1}$ level), when the concentrations are reduced from approximately 36 to $33 \mathrm{mg} \mathrm{kg}^{-1}$ in ethanol. 


\section{Conclusions}

The prototype vaporiser has proved to be effective at providing a stable vapour flow for over 8 hours and in our experience is more robust for continuous analysis of hydrocarboncontaining streams by process mass spectrometry than programmable thermal vaporiser systems. Furthermore the design is simple, cheap to build, compact and allows greater flexibility in set-up configuration. The sensitivity of analysis is good with detection limits at the sub $1 \mathrm{mg} \mathrm{kg}^{-1}$ level, as the gas entering the mass spectrometer is entirely from the sample, without dilution by a carrier gas. However, its use will be limited to those compounds that are thermally stable below the operating temperature of the vaporiser and transfer capillary.

Concentrations of benzene, toluene and o-xylene at the $\mathrm{mg} \mathrm{kg}^{-1}$ level in ethanol were accurately predicted and $3 \mathrm{mg} \mathrm{kg}^{-1}$ deviations in the concentration of the analytes in the ethanol sample stream could be detected on-line. Ethanol did not cause any interference on the ion measurements for the BTX analytes. In other samples, where such interference might not be avoided, the detection limits achievable will be impaired. Also, analytes that have similar mass spectra will further compound the sensitivity issue. In these situations, more complex calibration models will be required at best and in some cases detection at the required concentration level may not be achieved. Nonetheless, for process streams such as ethanol and similar compounds, where trace level detection of BTX impurities is required in close to real-time, analysis by process mass spectrometry with a vaporiser of the type described in this report will offer several advantages. These include improved sensitivity, simpler calibration and faster speed of analysis over techniques such as gas chromatography and spectroscopic methods. Rapid analysis of trace and bulk components in volatile liquid process streams by mass spectrometry will enable improved process control in the petrochemicals industry where process efficiency and product quality can be optimised and intermediate storage and waste reduced.

\section{Acknowledgements}

The support of EPSRC/DTI through LINK grant GR/R/19366/01 is acknowledged. EPSRC and CPACT are thanked for funding AWO's PhD studentship, and the Royal Society is thanked for the award of a University Research Fellowship to AN. 


\section{References}

1. P. C. Vanderaar, A. H. Stouthamer and H. W. Vanverseveld, J. Microbiol. Methods, 1989, 9, 281-286.

2. T. B. Colin, in Spectroscopy in Process Analysis, ed. J. M. Chalmers, Sheffield Academic Press, Sheffield, 2000, ch. 7, pp. 209-233.

3. A. Smith and M. J. Pettifor, Vacuum, 1982, 32, 175-181.

4. $\quad$ R. G. Wright, Journal of Process Analytical Chemistry, 1998, 4, 71-78.

5. J. L. Briesacher, M. Nakamura and T. Ohmi, J. Electrochem. Soc., 1991, 138, $3717-$ 3723.

6. J. Koprio, P. Muralt, G. Rettinghaus and G. Strasser, Vacuum, 1990, 41, 2106-2108.

7. G. D. Cessna, Advances in Instrumentation and Control, 1990, 45, 383-389.

8. K. D. Cook, K. H. Bennett and M. L. Haddix, Ind. Eng. Chem. Res., 1999, 38, 11921204.

9. P. Dell'Orco, J. Brum, R. Matsuoka, M. Badlani and K. Muske, Anal. Chem., 1999, 71, 5165-5170.

10. X. Yan, E. Sokol, X. Li, G. Li, S. Xu and R. G. Cooks, Angew. Chem. Int. Ed., 2014, 53, 5931-5935.

11. L. Zhu, G. Gamez, H. W. Chen, H. X. Huang, K. Chingin and R. Zenobi, Rapid Commun. Mass Spectrom., 2008, 22, 2993-2998.

12. J. S. Brodbelt, R. S. Willis and A. K. Chowdhury, Anal. Chem., 1992, 64, 827-829.

13. C. Didden and J. Duisings, Journal of Process Control and Quality, 1992, 3, 263-271.

14. J. C. Tou and D. Reddy, Anal. Chim. Acta, 1990, 229, 9-16.

15. W. B. Dunn, A. Townshend and J. D. Green, Analyst, 1998, 123, 343-348.

16. J. S. Lancaster, T. P. Lynch, T. Dutton, E. Becker, I. Beningfield and M. Noe, Analyst, 2002, 127, 1218-1223.

17. NIST Chemistry WebBook, http://webbook.nist.gov/chemistry/, Accessed 22nd May, 2013.

18. A. W. Owen, PhD Thesis, University of Strathclyde, 2006.

19. G. R. Flaten and A. D. Walmsley, Analyst, 2003, 128, 935-943. 


\section{Tables}

Table 1. Analyte fragments contributing to selected ions.

\begin{tabular}{|c|c|c|}
\hline $\mathrm{m} / \mathrm{z}$ & fragment & analyte \\
\hline 39 & $\begin{array}{c}{\left[\mathrm{C}_{3} \mathrm{H}_{3}\right]^{+}} \\
{\left[\mathrm{C}_{6} \mathrm{H}_{6}\right]^{2+}}\end{array}$ & $\begin{array}{c}\text { toluene and o-xylene } \\
\text { benzene }\end{array}$ \\
\hline 57 & - & - \\
\hline 73 & {$\left[\mathrm{C}_{6} \mathrm{H}\right]^{+}$} & benzene \\
\hline 77 & {$\left[\mathrm{C}_{6} \mathrm{H}_{5}\right]^{+}$} & benzene and o-xylene \\
\hline 78 & {$\left[\mathrm{C}_{6} \mathrm{H}_{6}\right]^{+}$} & o-xylene \\
\hline 91 & & toluene and o-xylene \\
\hline 92 & {$\left[\mathrm{C}_{7} \mathrm{H}_{7}\right]^{+}$} & toluene $\left(\mathrm{M}^{+}\right)$and o-xylene \\
\hline 106 & {$\left[\mathrm{C}_{7} \mathrm{H}_{8}\right]^{+}$} & o-xylene $\left(\mathrm{M}^{+}\right)$ \\
\hline
\end{tabular}


Table 2. The composition of benzene, toluene and o-xylene in ethanol prepared using the quaternary HPLC pump and analysed on line. The order of analysis is indicated by the sequence in the Run column. Concentrations are in $\mathrm{mg} \mathrm{kg}^{-1}$.

\begin{tabular}{ccccc}
\hline Sample & Run & Benzene & Toluene & O-xylene \\
\hline 1 & 6 & 0.00 & 0.00 & 0.00 \\
2 & 13 & 110.00 & 0.00 & 0.00 \\
3 & 14 & 0.00 & 109.00 & 0.00 \\
4 & 17 & 0.00 & 0.00 & 111.00 \\
5 & 8 & 82.50 & 0.00 & 0.00 \\
6 & 5 & 0.00 & 81.75 & 0.00 \\
7 & 2 & 0.00 & 0.00 & 83.25 \\
8 & 1 & 55.00 & 0.00 & 0.00 \\
9 & 9 & 0.00 & 54.50 & 0.00 \\
10 & 12 & 0.00 & 0.00 & 55.50 \\
11 & 4 & 27.50 & 0.00 & 0.00 \\
12 & 10 & 0.00 & 27.25 & 0.00 \\
13 & 7 & 0.00 & 0.00 & 27.75 \\
14 & 3 & 36.30 & 35.97 & 36.63 \\
15 & 16 & 27.50 & 54.50 & 83.25 \\
16 & 11 & 82.50 & 27.25 & 55.50 \\
17 & 15 & 55.00 & 81.75 & 27.75 \\
\hline
\end{tabular}


Table 3. The actual and predicted concentrations, $\%$ error, standard deviation $(n=10)$ and $\%$ RSD for benzene.

\begin{tabular}{|c|c|c|c|c|c|}
\hline Sample & $\begin{array}{c}\text { Actual } \\
\text { concentration } /\left(\mathrm{mg} \mathrm{kg}^{-1}\right)\end{array}$ & $\begin{array}{c}\text { Predicted } \\
\text { concentration } /\left(\mathrm{mg} \mathrm{kg}^{-1}\right)\end{array}$ & $\begin{array}{l}\% \\
\text { error }\end{array}$ & $\begin{array}{c}\text { Standard } \\
\text { deviation } /\left(\mathrm{mg} \mathrm{kg}^{-1}\right)\end{array}$ & $\%$ RSD \\
\hline 5 & 82.50 & 82.68 & 0.21 & 1.09 & 1.32 \\
\hline 8 & 55.00 & 55.08 & 0.14 & 0.84 & 1.52 \\
\hline 11 & 27.50 & 27.64 & 0.52 & 0.59 & 2.15 \\
\hline 14 & 36.30 & 35.87 & -1.18 & 0.74 & 2.05 \\
\hline 15 & 27.50 & 26.58 & -3.36 & 0.81 & 3.06 \\
\hline 16 & 82.50 & 81.53 & -1.17 & 0.97 & 1.19 \\
\hline 17 & 55.00 & 53.98 & -1.86 & 1.24 & 2.30 \\
\hline
\end{tabular}


Table 4. The actual and predicted concentrations, $\%$ error, standard deviation $(n=10)$ and $\%$ RSD for toluene.

\begin{tabular}{cccccc}
\hline Sample & $\begin{array}{c}\text { Actual } \\
\left.\text { concentration/( } \mathrm{mg} \mathrm{kg}^{-1}\right)\end{array}$ & $\begin{array}{c}\text { Predicted } \\
\text { concentration } /\left(\mathrm{mg} \mathrm{kg}^{-1}\right)\end{array}$ & $\begin{array}{c}\% \\
\text { error }\end{array}$ & $\begin{array}{c}\text { Standard } \\
\text { deviation/(mg kg-1) }\end{array}$ & \%RSD \\
\hline 6 & 81.75 & 80.87 & -1.08 & 0.74 & 0.92 \\
9 & 54.50 & 54.09 & -0.76 & 0.59 & 1.09 \\
12 & 27.25 & 26.66 & -2.16 & 0.44 & 1.64 \\
14 & 35.97 & 35.97 & 0.00 & 0.70 & 1.94 \\
15 & 54.50 & 55.39 & 1.64 & 1.04 & 1.87 \\
16 & 27.25 & 28.05 & 2.92 & 0.95 & 3.38 \\
17 & 81.75 & 82.25 & 0.61 & 0.96 & 1.17 \\
\hline
\end{tabular}


Table 5. The actual and predicted concentrations, $\%$ error, standard deviation $(n=10)$ and $\%$ RSD for o-xylene.

\begin{tabular}{rccccc}
\hline Sample & $\begin{array}{c}\text { Actual } \\
\left.\text { concentration/( } \mathrm{mg} \mathrm{kg}^{-1}\right)\end{array}$ & $\begin{array}{c}\text { Predicted } \\
\text { concentration } /\left(\mathrm{mg} \mathrm{kg}^{-1}\right)\end{array}$ & $\begin{array}{c}\% \\
\text { error }\end{array}$ & $\begin{array}{c}\text { Standard } \\
\text { deviation/(mg kg }\end{array}$ & \%RSD \\
\hline 7 & 83.25 & 83.52 & 0.32 & 0.87 & 1.04 \\
10 & 55.50 & 55.99 & 0.88 & 0.64 & 1.15 \\
13 & 27.75 & 28.45 & 2.52 & 0.50 & 1.76 \\
14 & 36.63 & 36.92 & 0.79 & 0.65 & 1.77 \\
15 & 83.25 & 83.51 & 0.31 & 0.93 & 1.12 \\
16 & 55.50 & 55.59 & 0.16 & 0.92 & 1.66 \\
17 & 27.75 & 27.94 & 0.68 & 0.82 & 2.94 \\
\hline
\end{tabular}




\section{Figure captions}

Figure 1. Vaporising device for direct introduction of liquid samples to the mass spectrometer.

Figure 2. Schematic diagram showing connection of the quaternary HPLC pump, vaporiser and mass spectrometer.

Figure 3. Mass spectra of a) benzene, b) toluene and c) o-xylene from the NIST spectral library. ${ }^{17}$ The vertical dashed lines indicate which ions were monitored.

Figure 4. The ion current profiles for selected ions (see legend) of pure ethanol changing to $111 \mathrm{mg} \mathrm{kg}^{-1}$ of o-xylene in ethanol.

Figure 5. The detection of deviations of $3 \mathrm{mg} \mathrm{kg}^{-1}$ in concentrations of about $36 \mathrm{mg} \mathrm{kg}^{-1}$ for a) benzene, b) toluene and c) o-xylene in ethanol. Data are shown for a time period of 3.3 hours; however, there is a delay of over 8 hours between scans 115 and 116 (indicated by arrow marking 'Next Day'). 


\section{Figures}

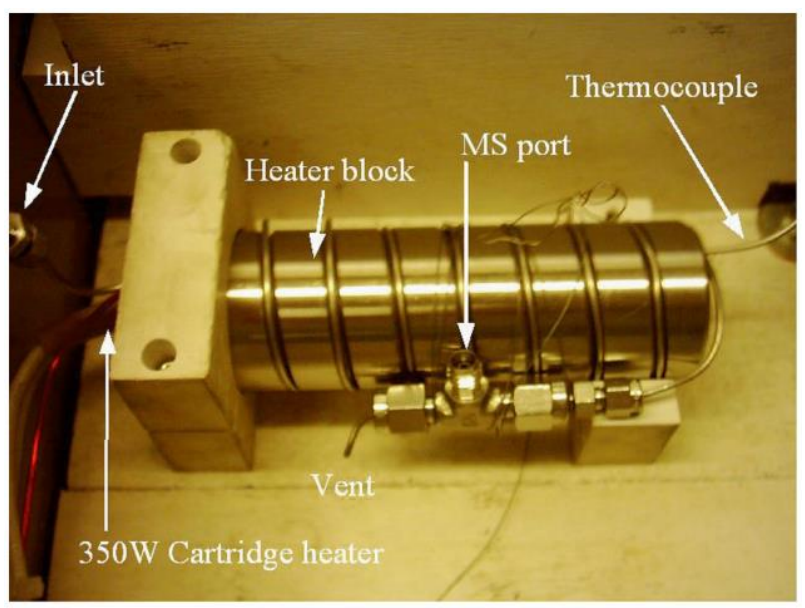

Figure 1

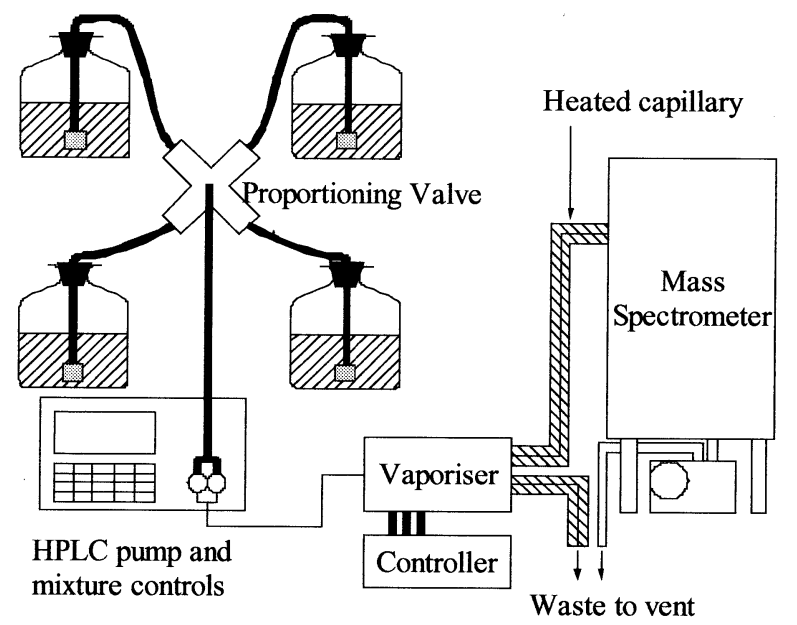

Figure 2 


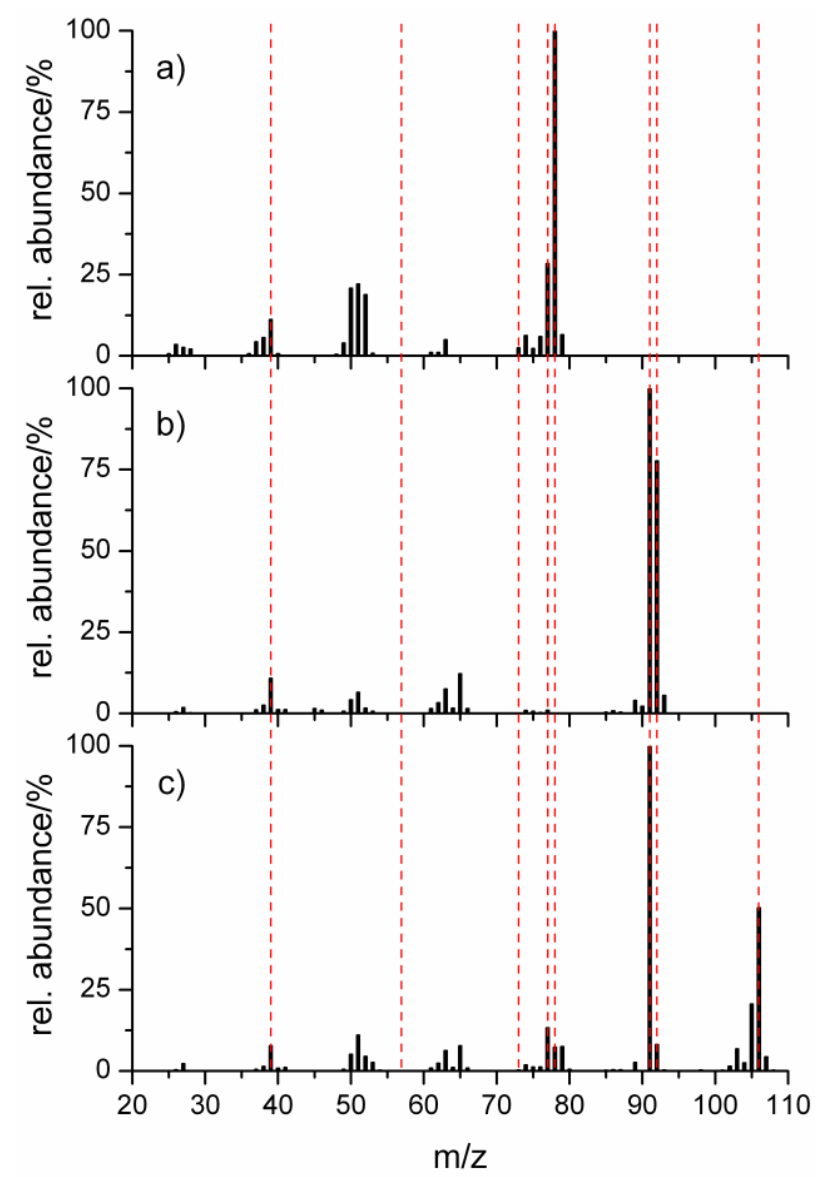

Figure 3

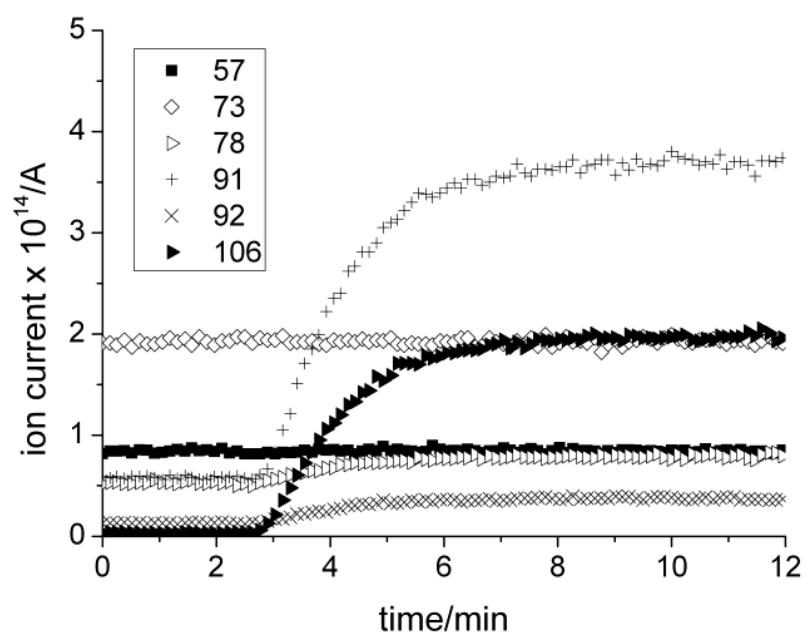

Figure 4 


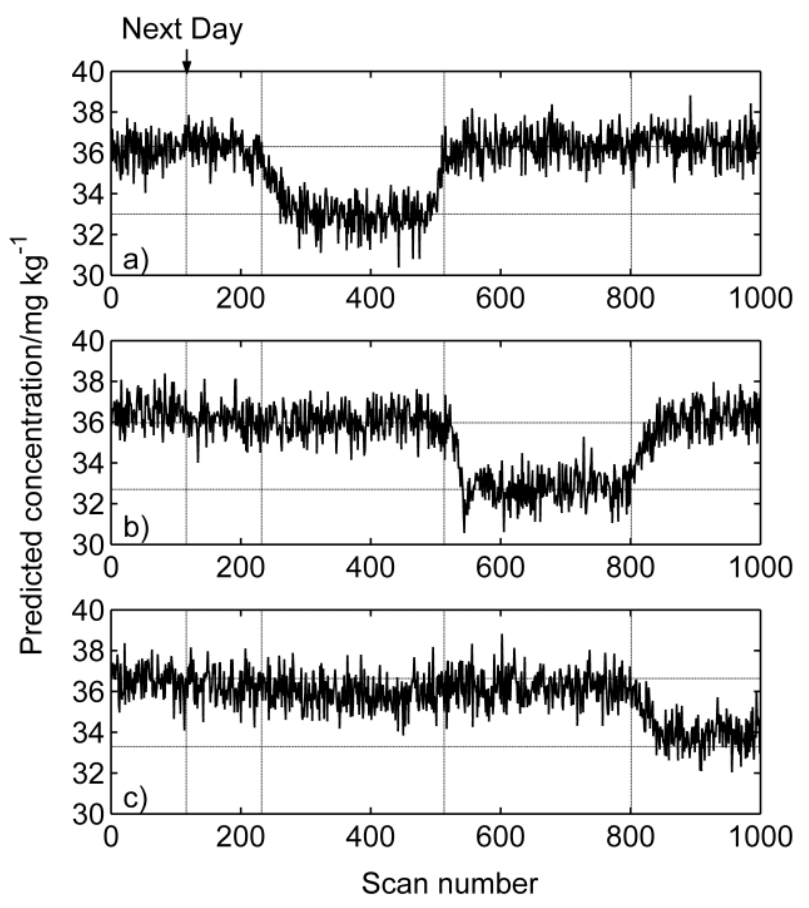

Figure 5 